\title{
Darcy Ribeiro e a universidade (cada vez mais) necessária
}

\author{
Roberto Leher ${ }^{1}$ - Universidade Federal do Rio de Janeiro (UFRJ)
}

Ao promoverem o ciclo de debates ${ }^{2}$ em homenagem ao acadêmico e professor Darcy Ribeiro, a Academia Brasileira de Letras o Arquivo Nacional e a Fundação Darcy Ribeiro contribuem, luminosamente, para quebrar o entorpecimento intelectual que se abate sobre o país. Intelectual iracundo, avesso ao conformismo, sempre nos instiga a pensar o Brasil de modo original, a partir do olhar (para ver e reparar, como nos insta José Saramago) das crianças e jovens mais expropriados e explorados, dos negros, dos povos originários e, como pude escutar dele próprio, de perceber o Brasil desde o interior, distintamente daquelas perspectivas que olham o país a partir do litoral, mirando o exterior. O evento, em todos os sentidos, é um grande acontecimento político e cultural.

É também uma oportunidade para falar de sua importância para a UFRJ. Darcy Ribeiro contribuiu muito para adensar a mística que envolve a Faculdade Nacional de Filosofia (FNFi), uma experiência que marcou muito a feição acadêmica e institucional da então Universidade do Brasil. De fato, entre 1939 e 1968, a FNFi produziu uma aura viva e pulsante que estimulou inovações teóricas e acadêmicas em todos os domínios do conhecimento. Qualquer estudo sobre o desenvolvimento institucional da UFRJ e das universidades públicas em geral não pode deixar de interpelar aqueles anos de intensa criatividade e de ousadia intelectual na produção do pensamento crítico. Seguramente, ao longo do período em que lá esteve, a voz, os gestos e a produção de Darcy Ribeiro ecoaram e brilharam de modo destacado.

Posteriormente, num contexto muito mais difícil, no período da ditadura empresarial-militar, quando o professor Darcy regressou do exílio para o Instituto de Filosofia e Ciências Sociais (IFCS), já no período "de abertura", a partir de 1979, se defrontou com uma universidade transformada pela ditadura. É importante lembrar que grandes professores da FNFi foram cassados em todas as áreas do conhecimento, inclusive Darcy, e que forças conservadoras, reacionárias mesmo, atuaram, de modo violento, para afastar a FNFi do pensamento crítico latino-americano (Eremildo Viana, então chefe do departamento da História, 'recomendara' não haver qualquer menção a Darcy Ribeiro, Celso Furtado, entre outros ${ }^{3}$ ) e das vertentes marxistas em geral. Mais do que isso, com a chamada "reforma de 1968", a própria FNFi foi desfeita, desmembrada em dez unidades acadêmicas. E o ambiente de perseguição, medo, delações tornou o ambiente acadêmico irrespirável.

O Instituto de Filosofia e Ciências Sociais e, mais amplamente, a UFRJ ainda não realizou homenagem a altura da trajetória de Darcy na instituição. Suas contribuições para pensar a educação básica e a universidade públicas, suas pesquisas e ensaios nos campos das ciências sociais, da antropologia e da etnologia são necessárias para o Brasil de hoje e poucos jovens tiveram oportunidade de conhecer essa fecunda contribuição para a ciência, a educação e a cultura no Brasil.

A sua obra e o seu exemplo são particularmente indispensáveis no atual contexto - 2017 - em que 
o país está em compasso de espera. Poucos se arriscam a projetar para onde o Brasil está indo. Conhecer as particularidades da formação econômico, social e cultural do Brasil é condição necessária para sairmos desse compasso de espera e o professor Darcy oferece outros prismas para melhor interpretarmos o Brasil e, assim, construir alternativas que possibilitem o bem-viver do povo brasileiro.

\section{A universidade necessária}

Decorrente de sua experiência na Universidade do Brasil e, notadamente, do projeto de construção da Universidade de Brasília (UnB), Darcy Ribeiro sistematiza muitas de suas ideias no livro $A$ universidade necessária, 1969, publicado pela Paz e Terra, obra revista e atualizada em 1975, por ocasião da segunda edição. Na quinta parte examina, justamente, o processo da $\mathrm{UnB}^{4}$.

A sua contribuição para forjar um modelo universitário original é preciosa. Ao implementarem o projeto da UnB, Darcy Ribeiro e Anísio Teixeira provocaram um tsunami diante da estrutura burocratizada e, de certa forma, engessada, das universidades brasileiras. A UnB foi uma linda rajada de ventos renovadores que abriu novas possibilidades para a universidade pública brasileira. A liderança de Darcy Ribeiro e de Anísio Teixeira possibilitou a reunião do que havia de melhor na inteligência brasileira, em todas as grandes áreas do conhecimento - Letras, biociências, física, tecnologias, ciências sociais e humanidades, cultura e arte -, reunindo professores, pesquisadores e profissionais que marcam a história da cultura brasileira: Cyro dos Anjos, Victor Nunes Leal, José Leite Lopes, Jayme Tiomno, Roberto Salmeron, Elon Lajes de Lima, Otto Gottlieb, Warwick Kerr, Antônio Cordeiro, Oscar Niemayer, André Gunder Frank, Rui Mauro Marini, Vânia Bambirra, Claudio Santoro, entre outros proeminentes professores.

Chamo atenção para o fato de que todo este esforço de reunir setores intelectuais diversos ganhou concretude na generosidade e na visão estratégica de Lúcio Costa que compreendeu que a universidade não deveria ser um lugar longínquo, afastado da cidade, mas deveria compor o coração da cidade para que a universidade pudesse ter a vibração da vida.

Os traços de Niemeyer possibilitaram uma concepção arquitetônica em que Institutos Centrais que dariam a formação básica do estudante deveriam estar agrupados, geminados, para que os estudantes pudessem circular livremente naquelas áreas, conhecer as diversas áreas do conhecimento e, com isso, adquirir uma cultura científica, tecnológica e cultural ampla e integrada, tornando-os sujeitos ativos na vida universitária, sujeitos que compartilham o desenvolvimento institucional. As Faculdades Profissionais, por sua vez, assegurariam a formação profissional sob o prisma da ciência aplicada. Os Órgãos Suplementares, voltados para a arte, cultura, esporte cumpririam a função, lato sensu, da extensão universitária.

A concepção de Anísio Teixeira e Darcy Ribeiro de que os estudantes compõem o co-governo da universidade demandou que os mesmos deveriam estar na instituição em horário integral, algo, até então, impensável no Brasil, e de que os professores deveriam conviver com os seus estudantes por meio do 
regime de dedicação exclusiva. A perspectiva do co-governo instaura um novo marco conceitual na vida universitária brasileira. É importante lembrar que, naquele contexto, a dedicação exclusiva não era uma prática usual nas universidades brasileiras. Inova também, à semelhança do que alguns institutos de pesquisa já haviam feito, na abolição do regime de cátedra, ainda presentes nas universidades brasileiras até a Lei 5.540/1968. O regime de cátedra assegurou maravilhosas experiências (como a de Sociologia, na USP, liderada por Florestan Fernandes) mas, é forçoso reconhecer, em sua maioria foi um entrave à renovação intelectual para a universidade.

O mote que leva à reflexão desse conjunto de intelectuais organizados e liderados por Darcy Ribeiro pode ser sintetizado numa expressão de um intelectual peruano muito importante, que também foi muito engajado na questão educacional e que morreu extremamente jovem: José Carlos Mariátegui. Ele dizia que o pensamento crítico na América Latina não deveria ser nem decalque, um conhecimento que se aplique a qualquer realidade, nem cópia; ao contrário, teria de ser um drama histórico original. Ou seja, um fazimento novo. Isto, certamente, marca a perspectiva epistemológica da UnB, que está instando estudantes, professores, intelectuais a engajarem a universidade num projeto de nação, em perspectiva crítica ao que Darcy conceituou como modernização reflexa. Não foi casual que os germes da teoria da dependência, ou, como se dizia então, sistema semicolonial de exportação (Gunder Frank, Rui Marini, Theotônio dos Santos, Vania Bambirra) nasceram nessa instituição.

Darcy Ribeiro está afirmando, sem subterfúgios, que a universidade deveria ser uma instituição política, uma instituição que produz conhecimento com uma perspectiva política de transformação da realidade, abrangendo a inserção do país na economia mundo; enfim, problematizando temas como tecnologia, cadeias produtivas que deveriam estar inseridas no país e a autonomia necessária destas, assim como de temas inseridos nas chamadas reformas de base (energia, telecomunicações, sistema bancário, reforma educacional etc.).

É importante também pontuar que a proposta de reforma universitária feita por Darcy Ribeiro, para a UnB, tem um viés novo para a universidade brasileira: uma maior aproximação com a América Latina. Ressoam valores, consignas, horizontes, discutidos no contexto das luta de Córdoba, em 1918, que foram uma espécie de matriz de um pensamento universitário "latinoamericanista". A perspectiva desenhada por Darcy Ribeiro para a UnB tem tonalidade aberta para a América Latina. Posteriormente, no exílio, Darcy dará colaboração importantíssima para a reforma universitária de diversos países, como Uruguai, Peru e Venezuela.

Outro aspecto a ser destacado foi sua concepção do papel dos intelectuais. O excelente texto sobre o livro de Darcy A universidade necessária, elaborado por Adélia Ribeiro e Glauber Matias ${ }^{6}$, chama atenção para um aspecto importante da formulação de Darcy Ribeiro que certamente está relacionada às influências de Mannheim. Em sua ação política, sustenta a necessidade dos intelectuais trabalharem a secularização do mundo para enfrentar manifestações de irracionalismos, apregoando a busca de projetos que transformem de maneira inteligente, deliberada e organizada, a sociedade. Um breve balanço de suas contribuições 
permite afirmar que, em sua concepção, a universidade deveria ser uma instituição estruturante de concepções e de projetos autopropelidos de nação. E não é casual que, posteriormente, ao sair da UnB, Darcy irá ocupar cargos importantes, como Ministro da Educação e, depois, como Chefe da Casa Civil.

Vale lembrar o contexto. Darcy Ribeiro, Anísio Teixeira, Paulo Freire estão atuando nas reformas educacionais; Celso Furtado e Chico de Oliveira estão operando em favor da industrialização da região Nordeste, enfrentando o poder do atraso na Superintendência do Desenvolvimento do Nordeste - SUDENE; Gianfrancesco Guarnieri, Oduvaldo Vianna Filho e os Centros Populares de Cultura da UNE estão forjando um novo teatro com novos horizontes culturais e políticos; Leon Hirszman, Rui Guerra, Joaquim Pedro de Andrade, Cacá Diegues estão criando novas estéticas e outros conteúdos para o cinema e Eduardo Coutinho para o cinema documentário; Geir Campos e Ferreira Gullar colocam em circulação nova poesia e Carlos Lyra, Nara Leão, Geraldo Vandré, Edu Lobo irrompem novas linguagens musicais, claramente de teor crítico ao capitalismo. O Movimento de Cultura Popular com Freire e Ariano Suassuna, permitem ecoar vozes de vanguarda do Nordeste. A Revista Civilização Brasileira, editada por Ênio Silveira, é um dos veículos dessas novas ideias.

É um ambiente político intelectualmente muito fervilhante. Diversos setores organizados da sociedade brasileira estão apontando a possibilidade de um desenvolvimento autopropelido da nação brasileira. Ou seja, um desenvolvimento que não estivesse marcado pela heteronomia de relações assimétricas do país com a economia mundial. Mas as forças burguesas dominantes não estavam desatentas em relação à conjuntura, iniciando um período de conspiração que levaria ao golpe empresarial-militar de 1964.

\section{Particularidade da revolução burguesa bloqueia a universidade necessária}

No início dos anos 1960, a crítica em relação à forma de inserção do país na economia mundial que estavam orientando, em grande parte, as organizações de esquerda, partia de um pressuposto que a realidade, desgraçadamente, veio mostrar que não tinha fundamento no mundo real: a de que existiam forças burguesas relevantes dispostas a protagonizar uma revolução democrática e nacional.

Uma das melhores sínteses sobre a estratégia da esquerda foi elaborada pelo Partido Comunista Brasileiro em sua Declaração de Março de 1958. Nesta, o partido propugna uma revolução nacional e democrática em aliança com os setores democráticos da burguesia, basicamente, setores industriais e antioligárquicos, como etapa necessária da futura revolução socialista.

Essa avaliação não era minoritária. Também a esquerda do Partido Trabalhista Brasileiro e os intelectuais que estavam organizados em torno do Instituto Superior de Estudos Brasileiros (ISEB), estavam, de alguma forma, trabalhando com o pressuposto de que haveria forças sociais, inclusive nas frações burguesas dominantes, dispostas a levar adiante um projeto autopropelido de nação (nacionaldesenvolvimentismo). 
A UnB seria a sua expressão espiritual, a sua expressão simbólica, capaz de catalisar um processo de desenvolvimento virtuoso. A revolução nacional adensaria a possibilidade de mudanças muito profundas em toda a sociedade brasileira, sintetizadas nas reformas de base de cunho liberal-democrático.

É importante destacar que a agenda fundamental das reformas, no final dos anos 1950 e início da década de 1960, incorpora, essencialmente, reformas que, em outros países, aconteceram no bojo de revoluções burguesas: reforma agrária; reforma energética; reforma do sistema bancário; reforma nas telecomunicações; reforma educacional - escola pública para todos, laica, gratuita, universal e obrigatória. Vários países tinham realizado isto. Essa hipótese de que haveria no Brasil a possibilidade de uma saída nacional, democrática, de matriz desenvolvimentista, era plausível. O grosso das forças sociais, naquela época, acreditava e apostava em tal via.

No Brasil, paradoxalmente, essas reformas não se harmonizaram com os anseios políticos e econômicos das principais frações burguesas. O que ficou evidente, conforme sabemos pelos acontecimentos históricos, foi que, de fato, o bloco de poder, usando um conceito de Poulantzas, já estava fortemente imbricado com o capitalismo monopolista. Um estudo clássico do Florestan Fernandes investigou o tema alguns anos depois: Sociedade de classes e subdesenvolvimento (1968) no qual o autor elaborou o vigoroso conceito de capitalismo dependente. Outros trabalhos sobre o golpe empresarial-militar de 64, como os de René Dreifuss, da Universidade Federal Fluminense, 1964: A conquista do Estado, permitem concluir que setores importantes da sociedade civil estavam operando no sentido de criar as condições para uma mudança não democrática do país.

Diferente da crença até então em voga no PTB e no PCB, Florestan Fernandes, em A Revolução Burguesa no Brasil (1975), propugna que a revolução burguesa no Brasil foi sui generis, uma revolução sem revolução, sem alteração fundamental na correlação de forças entre as classes fundamentais, configurando, antes, um processo autocrático, hostil aos direitos fundamentais da classe trabalhadora, o que inclui, certamente, a real universalização da educação pública. E ao achatar permanentemente os trabalhadores e suas organizações, a burguesia não se viu forçada a empreender reformas democráticas de cariz republicano.

É nesse escopo que se deu o desmonte brutal e radical da Universidade de Brasília. Uma obra de referência sobre a experiência da UnB é o livro do Roberto Salmeron ${ }^{7}$, um dos intelectuais atuantes na criação da Universidade de Brasília, que esteve à frente da área das ciências duras. Roberto Salmeron é um físico reconhecido que desenvolveu sua carreira na França. O autor nos mostra que, entre 1964 e 1965, 80\% dos professores da UnB foram afastados, seja porque foram diretamente demitidos da universidade, seja porque não tinham mais condições acadêmicas de trabalhar na instituição. Na primeira leva, por meio do Ato Institucional $\mathrm{n}^{\circ}$, Anísio Teixeira e Darcy Ribeiro foram cassados. A partir daí, sucessivas listas organizadas por Zeferino Vaz e Laerte Ramos de Carvalho, os reitores nomeados após o golpe empresarialmilitar, nomeiam os docentes a serem retirados da instituição. É necessário ressaltar: $80 \%$ das pessoas que organizaram, criaram e sonharam com a construção da Universidade de Brasília foram banidas. 
Este esforço de construir uma universidade a contrapelo, usando uma expressão de Walter Benjamin, ou seja, remando contra a maré, foi algo muito luminoso para pensarmos a educação brasileira e, sobretudo, para discutir e pensar possibilidades (e dolorosas dificuldades) para uma reforma universitária.

A ditadura bloqueou a ideia de agência humana, segundo a qual os seres humanos podem transformar a realidade de maneira democrática, organizada e, sobretudo, referenciada em conhecimentos científicos. O cerceamento ditatorial marca um elemento importante, porque confirma que o poder do atraso não está em antípoda com a "modernização" capitalista. A ditadura impõe um constrangimento de natureza epistemológica, ao criar um ambiente universitário (pela força e pela cooptação) "adaptativo" frente ao conhecimento científico produzido em outros contextos e à divisão internacional do trabalho, vinculando, ou tentando vincular, a universidade à modernização conservadora.

É um truísmo afirmar que toda universidade é uma instituição internacional que interage (e precisa interagir) com os principais centros de conhecimento do mundo, para criar conhecimento novo para enfrentar os problemas nacionais, reafirmando a pertinência da universidade com os desafios e os problemas dos povos, em especial com os desvalidos e os expropriados. Isso requer o reconhecimento da humanidade de todo o povo brasileiro, notadamente dos negros, dos povos indígenas e dos camponeses banidos da terra. Neste prisma, a universidade é pensada como um espaço por meio do qual a expressão das lutas dos povos possa se irradiar. Tal intento encontrou obstáculos cada vez mais perigosos, como se depreende do Ato Institucional $n^{0} 5$ (1968) e do Decreto 477 de 1969, justamente o período em que foi editada a Lei 5.540/1968, a lei da chamada reforma universitária.

A produção de conhecimento original requer o exercício da crítica às perspectivas eurocêntricas, aos esquemas de pensamentos extremamente adaptativos à uma posição subordinada do país à economia do mundo, como se esta subordinação fosse mérito, como se a subordinação fosse sinal de modernidade, de civilidade, de "progresso". De certa forma, quase que naturalizando a perspectiva de uma heteronomia de pensamento. A busca da autonomia intelectual e da autonomia de centros de produção de conhecimento passa a envolver pressões e ameaças reais nas universidades. Darcy Ribeiro ousou buscar a crítica e pagou um preço elevado por isso. Não é casual que no primeiro Ato Institucional da ditadura, o Ato Institucional $\mathrm{N}^{\mathrm{O}}$ 1, três grandes educadores foram afastados: Darcy Ribeiro, Anísio Teixeira e Paulo Freire. A seguir, Florestan Fernandes e tantos outros foram retirados da vida universitária. Somente com a chamada abertura democrática, em especial, com a anistia, alguns desses quadros puderam voltar à universidade, mas, no novo contexto, em condições muito difíceis, no rastro da Crise da Dívida de 1982 e das décadas neoliberais vindouras. A agenda universitária, nesse contexto, era outra. As marcas da universidade constrangida a operar a modernização conservadora seguiram tensionando o fazer universitário, não mais pela força direta, mas a partir da autonomização do aparato tecnocrático jamais submetido ao escrutínio democrático.

\section{Ideias para a universidade necessária ao Brasil}


Darcy Ribeiro propôs uma aceleração evolutiva. A ideia de aceleração é, sobretudo, de uma aceleração que projeta o tempo futuro, realça o papel teleológico e construtor das forças sociais, e não adaptativo. Esta formulação de Darcy se aproxima, de alguma forma, de uma formulação de Antônio Gramsci muito vigorosa em termos explicativos, políticos, que é a criação de uma vontade nacional popular. Darcy está propugnando uma aceleração evolutiva inscrita no movimento de arregimentar forças para construção de uma vontade nacional capaz de transformar a realidade brasileira. Nosso autor pôde interagir e conhecer a realidade da produção do conhecimento brasileiro no período em que circulou pelo Brasil. Por isso, confiava que o país poderia ter uma universidade pujante também nas áreas tecnológicas e das ciências “duras”, mas críticas em relação à modernização reflexa.

Com efeito, o país necessita de tecnologias capazes de lastrear um projeto autopropelido de nação, a exemplo da construída para a extração de petróleo em águas profundas, o pré-sal. Ou de tecnologias como a fixação biológica de nitrogênio, possibilitando alimentos mais baratos e de melhor qualidade, reduzindo insumos químicos. Enfim, tecnologias comprometidas com um desenvolvimento nacional com encadeamentos produtivos mais autônomos e que alicercem a nação num patamar em que todo o povo coubesse dentro da nação. Darcy não se conforma com um Brasil em que negros, quilombolas, favelados, povos indígenas, camponeses são colocados à margem da nação.

Para isso, é preciso uma universidade iracunda, uma expressão que ele gostava de usar. Uma universidade não conformista, uma universidade que projetasse, politicamente, outra forma de construção da nação. É uma perspectiva que, atualmente, está sob fortíssima tensão no Brasil. O Brasil atual mostra a atualidade da obra de Darcy Ribeiro. Particularmente para as novas gerações, é fundamental esse debate, dele e da geração que esteve em interação com o pensamento crítico feito no Brasil.

O orçamento de 2017 do Ministério das Ciências e Tecnologias é praticamente um terço do orçamento de três anos atrás. Neste momento está sendo discutida a relativização do conteúdo nacional. A Emenda Constitucional $n^{\circ} 95$ objetiva reduzir as despesas primárias a patamar semelhante ao dos piores anos da ditadura empresarial-militar, inviabilizando todo o conteúdo social da Constituição de 1988. A crise da Universidade do Estado do Rio de Janeiro (UERJ), da Universidade Estadual do Norte Fluminense (UENF), da Centro Universitário da Zona Oeste (UEZO), confirma que está em curso no país uma política antiuniversitária. As universidades Federais encontram-se estranguladas em termos orçamentários, o que pode comprometer a modesta expansão da última década.

O objetivo da presente exposição não é levantar as mazelas e os problemas que estamos vivendo na universidade, mas chamar atenção para o fato de que aquele propósito político-estratégico direcionado para a efetivação de um sistema complexo de educação básica e superior capaz de secularizar a vida social, possibilitando que todos que possuem um rosto humano possam fazer um uso crítico e autônomo da razão, está sob severo risco.

Cada vez mais, temos no país projetos, iniciativas parlamentares, ações judiciais, que subtraem a 
liberdade de pensamento. Isto é algo que aparentemente ocorre aqui e ali, mas, se examinarmos a Comissão de Educação - um lugar em que a trajetória do Darcy foi importante no Senado, espaço muito importante para pensarmos a educação - observamos inédita iniciativa contra a escola laica, científica, universal, e de igual qualidade para todo o povo.

Nestes espaços está sendo difunda a ideia de uma educação que não possibilita uma cultura geral, tal como estava no projeto da UnB com os ciclos básicos em horário integral. Não é casual que na reforma do Ensino Médio chegou-se a propor, claramente, a exclusão da área de artes ou a exclusão de toda área vinculada às ciências sociais, à sociologia, à filosofia, como aspectos que atrapalham aquilo que as pessoas devem saber, um pouquinho de português e um pouquinho de matemática.

Há um trecho da Universidade Necessária em que Darcy acentua o papel obrigatoriamente político das instituições em que estudantes e professores deveriam ter uma liberdade ilimitada de pensamento. $\mathrm{Na}$ abertura da parte $\mathrm{V}$ do referido livro, ressalta que as ideias, as utopias, devem nos fazer mover em prol da transformação "radical" da realidade, particularmente, da universidade frente ao conformismo com a modernização reflexa. Conforme o epistemólogo Gaston Bachelard, o direito de sonhar é necessário para o conhecimento novo.

Todo esse esforço da geração de intelectuais que conviveram com Darcy Ribeiro, consignado nos livros, nas experiências que foram feitas posteriormente, inclusive aqui no Estado do Rio de Janeiro, com os Centros Integrados de Educação Pública (CIEP), no qual tive a honra de trabalhar durante um período sob a coordenação de Darcy Ribeiro, precisa ser recuperado e conhecido, estudado, não como modelo, mas como uma produção importante de conhecimento que nos abriu possibilidades históricas.

Darcy Ribeiro incorporou a função do intelectual público. Em momentos tão difíceis é muito importante que possamos reconhecer, valorizar, celebrar a coragem daqueles que contribuíram para tornar pensáveis os grandes temas. Este papel de intelectual público permitiu que o pensamento de Darcy Ribeiro se capilarizasse na sociedade brasileira. Ao lado de Jango, ousou pensar um Brasil democrático com as reformas de base; junto com Brizola, ousou pensar uma educação digna para a classe trabalhadora.

Sua vitalidade, a efervescência de sua produção, sua inquietação intelectual, o brilho de seus olhos quando falava das mudanças necessárias para superar as injustiças e a dor das pessoas que vivem do próprio trabalho e são exploradas, o seu permanente engajamento na produção de conhecimento novo para transformar radicalmente a realidade, modificando a correlação de forças entre as classes, tudo isso nos inspira. É um legado importante para todos que estão, hoje, lutando por um mundo que reconheça o direito de todos que têm um rosto humano ao bem viver.

É também um momento de celebração de uma trajetória intelectual e organizativa que deve seguir nos inspirando e motivando a fazer essa travessia complexa que estamos trilhando hoje no Brasil, em prol da dignidade e dos direitos sociais para todos que têm um rosto humano. 
Rio de Janeiro, 02 de Novembro de 2017

\begin{abstract}
${ }^{1}$ Reitor da Universidade Federal do Rio de Janeiro (UFRJ). Doutor em Educação pela Universidade de São Paulo (USP), Professor da Faculdade de Educação e do Programa de Pós-Graduação em Educação da Universidade Federal do Rio de Janeiro (UFRJ), Pesquisador do Conselho Nacional de Desenvolvimento Científico e Tecnológico (CNPq), Cientista de Nosso Estado FAPERJ, colaborador da Escola Nacional Florestan Fernandes (ENFF).

${ }^{2}$ A conferência foi gravada, e, posteriormente, transcrita por Gabriel Arcanjo Pereira da Silva.

${ }^{3}$ FERREIRA, Marieta de Moraes. Ditadura militar, universidade e ensino de história: da Universidade do Brasil à UFRJ. Cienc. Cult., São Paulo, v. 66, n. 4, p.32-37, 2014. $<$ http://cienciaecultura.bvs.br/scielo.php?script=sci_arttext\&pid=S0009-67252014000400012\&lng=en\&nrm=iso $>$. Access on 14 Oct. 2017. http://dx.doi.org/10.21800/S0009-67252014000400012.

${ }^{4}$ RIBEIRO, Darcy, A universidade necessária (2a Ed.), Rio de Janeiro: Editora Paz e Terra, 1975.

5. Leher, R. Reforma universitária de Córdoba, noventa anos. Um acontecimento fundacional para a universidade latino-americanista. In: Sader, E., Aboites, H. e Gentili, P. La reforma universitaria: desafíos y perspectivas noventa años después. Bs.As. CLACSO, 2008.

${ }^{6}$ RIBEIRO, A. M. e MATIAS, G. R. A universidade necessária em Darcy Ribeiro: notas sobre um pensamento utópico. Rev. Ciências Sociais, Unisinos, 42(3), set/dez. 2006, disponível em http:// revistas. unisinos.br/index.php/ciencias sociais/article/view/6034

${ }^{7}$ SALMERON, R. A. A universidade interrompida: Brasília 1964-1965. Brasília: Ed. UnB, 1999.
\end{abstract}

